\title{
O Crepúsculo do Conhecimento Contábil
}

\author{
Autor: Alexandre Assaf Neto \\ Doutor em Finanças pela USP, Professor Adjunto da UNB \\ O Autor deste trabalho é economista, que por necessidade de melhor
compreender as leis da Economia e por prazer estudou um pouco de contabilidade
}

\section{Introdução}

A Contabilidade tem sido alvo, nos últimos tempos, de alusões no mínimo constrangedoras e equivocadas a respeito da importância de seus profissionais e, principalmente da e representatividade de suas informações. São incomodas e causam perplexidade, por exemplo: quando orientam seus protagonistas e usuários a regredirem às humildes e ultrapassadas origens do principio do custo histórico puro. São cerceadoras quando propõe limites temporais à atividade contábil, fixando períodos longos, arbitrários e variáveis para aqueles que entendem de contabilidade, ao deferem a ampla superioridade do Fluxo de Caixa sobre a Demonstração de resultados (1)

Há de se convir, no entanto, como atenuante ao problema, que o conhecimento contábil não é de assimilação imediata e universal. Confunde-se com certa freqüência, capital com lucros, correção monetária com rendimentos, inflação própria com preços de reposição, regime de competência com regime de caixa, e assim por diante.

Depara-se com balanços de bancos, por exemplo, ostentando receitas de operações de crédito negativas e de despesas captação de CDB positivas constitui-se, compreensivelmente, num desafio.

De maneira sucinta, esse artigo se propõe a discutir a informação contábil isenta de modismos e posições irracionais. Essa provocação literária é urgente e imprescindível no momento atual, antes que se culpe o gatilho e se desenvolva o dedo que o disparou.

A economia brasileira é estruturalmente viesada: altas taxas de juros e de inflação, momentos de forte superavaliação do cruzeiro perante as outras moedas mais estáveis, entre outros, são desafios aos informes gerenciais. Taxas de juros em curto prazo, mais altas que as de longo prazo revogam a lei risco x retorno; o controle de preços caduca a lei de oferta e procura, e assim por diante.

Este é o cenário em que a Contabilidade se insere, devendo atuar de forma singela, porém com confiabilidade e atuar de forma singela, porém com confiabilidade e representatividade. Ao surgirem, de fóruns privilegiados, propostas como a de abolir a inflação dos balanços, e não da economia como seria de se esperar, alimenta-se o crepúsculo de conhecimento contábil.

\section{Os Demonstrativos Contábeis e sua Inserção no Cenário Econômico}

É entendido que o problema do fenômeno inflacionário não recai sobre a taxa percentual periodicamente calculada.

Ao contrario, se estabelece a partir do entendimento do processo de perda do poder aquisitivo que a inflação determina nos agentes econômicos. De forma mais significativa, o empobrecimento da capacidade de compra não é linear, evidenciando-se com diferentes intensidades. Como resultados, são estabelecidos profundos e danoso desequilíbrio na economia, afunilando mais pronunciamento o topo da pirâmide de rendimentos.

A informação contábil pura, produzida consoante o princípio do custo histórico, torna-se perigosamente enganosa em ambientes inflacionários, disseminando em muitos um permanente estado de ilusão monetária. Ao confiarem honestamente nos "puristas" dos valores históricos, as pessoas passam a admitir que estão obtendo ganhos em seus negócios, sem se darem conta (ou observarem tardiamente) da realidade do conhecimento.

O aviltamento da moeda determina, para suprir as necessidades cada vez maiores de gastos, uma demanda exponencialmente crescente por recursos financeiros. A empresa, por seu lado, para repor ativos consumidos e corroídos pela inflação, precisa reter partes cada vez maiores dos resultados operacionais para poder operar seus negócios de maneira competitiva.

É exatamente essa perda de poder de compra, enaltecendo os valores reais dos demonstrativos financeiros, que a contabilidade através da sistemática de correção monetária, tem o dever de revelar. O usuário da informação contábil, tem o direito de conhecer o nível de desgaste sofrido pela empresa ao se exporem conjunturas inflacionarias, manipulando os resultados de ganhos e perdas dos itens monetários.

Os resultados operacionais que a Contabilidade com correção monetária e Demonstração de Resultados (e não alternativamente de Fluxo de Caixa) procura revelar são aqueles originados estritamente da atividade empresarial, independentemente da forma pela qual a empresa encontra-se financiada.

A correção monetária integral - infelizmente ainda não totalmente compreendida por alguns críticos da Contabilidade permite que se identifique os resultados reais oriundos exclusivamente dos ativos e aqueles valores formados por 
decisões passivas de captação. Essa separação do desempenho da empresa é fundamental, sem a qual qualquer avaliação econômica mais séria estaria totalmente comprometida.

É ilustrativo que se acrescente que, ao não considerar inflação em seus demonstrativos, isto é, ao privilegiar o custo histórico puro,, a tendência seria as empresas com maior volume de vendas a prazo apresentam os melhores resultados operacionais. Evidentemente, as perdas pela postergação do recebimento estabelecem lucros nominais ilusórios bastante elevados e sério comprometimento na capacidade em repor os estoques consumidos.

Os ganhos não operacionais no mercado financeiro não são manobras contábeis, os resultados reais, obtidos após a devida depuração dos efeitos inflacionários, estão claramente demonstrados àqueles que dominam o assunto. Ao ignorar a variação nos índices gerais de preços, constata-se que a relação receitas financeiras/vendas das companhias de capital aberto no Brasil atingiu a marca média de 24,2\% em 1989.

Ao se isolar os ganhos meramente inflacionários, que representam mais corretamente reposição do capital investido, a taxa cai para 5\%. Essa revelação contábil contribui para suavizar o rigor de acusação, tão em moda atualmente, de que as empresas brasileiras, em sua média, obtém a maior parte de suas receitas no mercado financeiro (em atividades especulativas), e não em sua atividade operacional.(2).

Uma característica bastante acentuada nas empresas brasileiras é a elevada margem bruta que apresentam em seus relatórios contábeis (lucro bruto/vendas). Em valores puramente históricos, o resultado médio de 1.989 das companhias de capital aberto atingiu mais de $48 \%$, marca altamente expressiva em qualquer economia do mundo.

Em verdade o resultado não demonstra melhor desempenho produtivo, e sim a ilusão monetária proveniente de se relacionar valores representativos de poder de compra de diferentes períodos. Depurando-se os efeitos da inflação, a margem bruta reduz-se para somente $27 \%$, quase a metade do registrado em valores históricos.

Em conclusão, não existe lucro da contabilidade, como também não existe lucro da Economia, da Administração, etc.

Rigorosamente, encarando-se o fato, a idéia mais representativa de lucro foi apresentada por Hicks (3). Lucro segundo Hicks, "é tudo aquilo que se pode gastar hoje e se sentir tão rico quanto era ontem". Evidentemente, este conceito somente se realiza no momento em que a Contabilidade ignora seus resultados históricos e passa a operar em valores corrigidos.

De maneira idêntica, o denominado "cipoal de provisões, correções monetárias..." é indispensável para que o usuário que compreenda os registros contábeis se posicione de forma aproximadamente certa com relação à situação da empresa, e não exatamente errada como seria inevitável no caso destes valores serem omitidos. É preciso que se conclua que na Contabilidade ainda a essência prevalece sobre a forma.

\section{Demonstração de resultados e fluxo de caixa: alternativas mutuamente excludentes ou complementares?}

É constrangedor aos parâmetros do conhecimento contábil e financeiro debruçar-se co discussões sobre a mutua excludência entre as Demonstrações Contábeis e o Fluxo de Caixa, principalmente quando se tem sensibilidade para apreciar o intimo relacionamento que apresentam.

Em verdade as Demonstrações Contábeis constitui-se num retrato temporal de movimentos de caixa da empresa.

Identificam estas demonstrações valores em disponibilidade, receitas a serem realizadas e ainda não pagas, além de outros direitos e obrigações. Para um mais atento observador, é evidente que o lucro circula pelo caixa da empresa.

A diferença fundamental existe entre a Demonstração de Resultados e o Fluxo de Caixa e a elaboração destes instrumentos segundo, respectivamente, o regime de competência e o de caixa.

O lucro por competência de um determinado período é a melhor expressão da capacidade econômica (geração de resultados) e financeira de uma empresa. O conhecimento exclusivo dos fluxos de recebimento e pagamentos de mercadorias, principalmente por não ocorrerem ao mesmo tempo, é incapaz de revelar se o negócio está produzindo lucro ou prejuízo.

Um exemplo bem pertinente são os financiamentos que prevêem carência no pagamento de seus encargos. Não computar seus juros como despesas durante o período de utilização dos recursos e somente considera-los quanto de seu efetivo desembolso financeiro é uma decisão equivocada, comprometendo todo o fluxo de resultados da empresa.

Há uma evidente vinculação entre as Demonstrações Contábeis e o Fluxo de Caixa, principalmente sabendo-se que a moeda é o denominador comum de todas as operações. Em horizontes mais longos, o lucro se expressa em termos de riqueza monetária, vinculando-se assim ao conceito do Fluxo de Caixa.

No entanto, a necessidade de acompanhar o desempenho da empresa determina a necessidade de se apurar periodicamente à demonstração de resultados, pelo regime de competência.

Uma avaliação conjunta deste instrumento com o Fluxo Financeiro permite um melhor conhecimento do desempenho econômico e da posição financeira de qualquer empresa. 
As Demonstrações Contábeis e o Fluxo de Caixa não são excluístes. Ao contrario, apresentam méritos relevantes, específicos e complementares. Para uma análise econômica do retorno sobre o investimento, a Demonstração de Resultados e o Balanço Patrimonial são as únicas peças habilitadas ap processo. Para a avaliação de uma situação financeira corrente e liquidez, o conhecimento do Fluxo de Caixa permite melhores inclusões.

Portanto, não há predomínio de um sobre o outro. As informações dos Demonstrativos de complementam e devem ser usadas concomitantemente. Talvez a declarada preferência de alguns pelo Fluxo de Caixa seja em razão deste ser mais fácil de compreender que os fluxos contábeis produzidos pelo regime de competência.(4)

\section{A Inflação Especifica das Empresas}

Enquanto alguns autores propõem vigorosamente à volta ao principio do custo histórico mesmo em inflação, ganha evidencia, de outro lado o uso da inflação interna das empresas como alternativa ao índice geral de preços da economia. Em outras palavras, enquanto o mundo contábil discute qual o índice de preços que deve ser adotado para se apurar resultados mais representativos ou especialmente, quais os critérios que devem ser adotados para se aprimorar o método do custo de reposição, defronta-se ultimamente com a proposta de cada empresa usar a sua própria inflação e publicar seus resultados a partir destes percentuais.

A utilização especifica da inflação da empresa quando tratada aos níveis gerenciais, de avaliação e controle dos indicadores financeiros, é bastante saudável recomendável.

No entanto, propôr-se usar esta taxa de inflação como alternativa ao índice geral de preços da economia para apuração das demonstrações contábeis é profundamente questionável.

Em primeiro lugar, pelos enunciados apresentados, parece haver algumas duvidas sobre o que efetivamente significa inflação geral, inflação especifica e o custo de reposição.

Apesar de todo metodologicamente poderem ser calculados de modo semelhante, os dois primeiros índices de inflação não representam a mesma coisa, provocando sensíveis alterações na definição do lucro.

O índice de inflação geral é conseqüência de uma variação ponderada nos preços de inúmeros bens e serviços consumidos na economia. É uma média, indicando portanto que nem todos os itens subiram exatamente igual à taxa apurada.

Alguns podem ter crescido mais que a taxa de inflação, outros podem ter acompanhado mais aproximadamente e alguns, ainda, podem ter até sofrido reduções de preços. O índice especifico de preços (de uma empresa, de um setor econômico, etc.) é apurado com base nos itens consumidos exclusivamente por aquele segmento.

A inflação interna de uma empresa pode existir mesmo quando a inflação geral da economia for nula. Em geral, estas duas taxas de inflação não são iguais, sendo o índice especifico de maneira independente do índice geral de preços.

Ao adotar o índice especifico de inflação na apuração do lucro, a empresa se volta para a correção de cada ativo a ser reposto através de um percentual médio ponderado. Neste cômputo do índice são levadas em consideração as variações ocorridas nos preços das mercadorias, nos encargos financeiros, nas tarifas publicas, nos salários, etc.

Neste momento surge uma evidente preocupação: é valido, por exemplo, corrigir-se os custos das vendas por índice que reflete uma série enorme de diferentes variações de preço, os quais pouco ou nada têm a ver com o ativo a ser reposto? Ou é mais correto utilizar-se o próprio preço de reposição do ativo? Imagine, por outro lado, corrigir-se um ativo permanente, de elevada tecnologia e forte incremento de preços, por um índice médio de inflação da empresa em cuja metodologia de ponderação encontra-se uma matéria-prima com forte predominância nos custos e baixíssima variação de preços. $O$ ativo permanente deve ser corrigido pelo seu custo de reposição específico, bem mais alto, ou pela inflação média interna da empresa?.

Uma questão que permanece ainda é quando o índice específico de inflação superar o índice geral da economia.

Qual dos dois índices deve a empresa utilizar para corrigir seus preços de vendas, dividendos, etc. Da mesma forma, se a inflação interna for menor que a inflação geral, a opção pela variação especifica pode provocar a descapitalização da empresa.

Ao trabalhar com índice especifico de inflação, a em,presa pode altera-lo simplesmente modificando as quantidades e participação de seus custos de despesas. Estas modificações podem ocorrer por razões verdadeiras da empresa?

Em verdade a inflação interna é tão (ou mais) inverdadeira quanto à inflação geral da economia. Martins (6) conclui o raciocínio: "...a idéia de que a inflação própria é a verdadeira. Esta talvez só pudesse ser considerada no plano das intenções, mas estas nem sempre passam deste estágio". 


\section{Conclusões}

É preciso com a maior acuidade, traçar-se um perfil da estrutura típica da economia brasileira e suas mais relevantes repercussões sobre a vida contábil e financeira das empresas.

O processo inflacionário brasileiro além de perdurar a várias décadas, caracteriza-se por apresentar taxas bastantes significativas e alterações abruptas de um período para outro. Propostas de não levar em conta esta realidade na apuração das demonstrações contábeis causam grande perplexidade. É inadmissível comparar-se, por exemplo, com o valor de uma venda a ser recebida daqui a trinta dias com o custo da mercadoria adquirida 60 dias atrás. Da mesma forma, não há nenhuma comparabilidade entre o volume de vendas de dois exercícios consecutivos se os valores não estiverem expressos em moeda de idêntica capacidade de compra.

$\mathrm{Na}$ verdade, é preciso trabalhar-se com uma moeda constante e mais refinadamente, o valor presente, para que as demonstrações promovam maior confiabilidade e a Contabilidade exercite adequadamente a sua função nem sempre compreendida pelos não contadores. Propor a volta do principio do custo histórico puro é inutilizar toda a capacidade informativa das demonstrações contábeis, iludindo seus usuários e impedindo maior gerenciamento das empresas.

A proposta de substituição da Demonstração de Resultados pelo Fluxo de Caixa, requer identicamente um melhor entendimento da contabilidade e o seu potencial informativo pelos agressos de outras áreas de saber. São instrumentos importantes que se complementam, mas não se excluem. A predição do desempenho econômico e patrimonial da empresa, assim como umas avaliações de sua posição atuais, somente podem ser entendidas pelo Balanço de Demonstração de Resultados. O Fluxo de Caixa é importante como instrumento complementar às Demonstrações Contábeis, nunca alternativo.

Permite, ao trabalhar em regime de caixa, uma melhor visualização da liquidez e posição financeira de curto prazo da empresa, sendo impróprio para análise envolvendo horizontes mais longos.

Em suma, o Fluxo de Caixa e as Demonstrações Contábeis não são mutuamente excludentes, mas sim complementares. É fundamental compreender-se o que se entende por regime de competência e regime de caixa para se dominar a forte vinculação existente entre as Demonstrações Contábeis e o Fluxo de Caixa.

A preocupação maior entre os especialistas em contabilidade de todo o mundo é discutir avanços no método de método de custo corrente corrigido, estando descartada por inconsciência, qualquer tentativa de qualificar a inflação especifica das empresas para a apuração das Demonstrações contábeis. Essa discussão sofreu algum retrocesso no Brasil com a proposta de substituir o índice geral de preços pelo índice da empresa em particular.

O índice especifico de inflação, conforme foi demonstrado, não apresenta qualidades para ser usado na mensuração patrimonial e dos resultados empresariais, em substituição ao índice geral de preços da economia. Suas condições são menores ainda de se colocar como alternativa ao custo de reposição. Usos não genéricos e indiscriminados da inflação especifica são possíveis, mas tendo-se sempre o cuidado de confrontar os cálculos como índice global de inflação da economia.

Em suma, este artigo não teve em nenhum momento a intenção de inovar ou apresentar novas teorias ou formulações contábeis. A preocupação maior foi voltar-se contra a disseminação de idéias e propostas absolutamente equivocadas na área de Contabilidade, as quais poderão servir de cilada para incautos usuários de seus fluxos de informações.

\section{Notas}

(1) Este artigo é um posicionamento às várias opiniões formalmente manifestadas sobre a Contabilidade e que denotam um expressivo desconhecimento do assunto. São posições perigosas, com forte risco de contagio pois propugna 0 errado através do menor esforço possível. É defendia a volta aos padrões históricos puros para a Contabilidade mesmo em contextos inflacionários, a supremacia do Fluxo de Caixa sobre as demais Demonstrações Contábeis, a correção integral e o custo corrente de reposição são criticamente ignorados, etc.

(2) Excelente pesquisa sobre o desempenho das companhias de capital aberto no Brasil é desenvolvida há vários anos pelo Departamento de Contabilidade da FEA/USP, através da FIPECAFI-IPECAFI. Os dados apresentados foram extraídos da publicação de 1990 relativa ao Setor Industrial-Privado.

(3) Hickas, J.R. Value and Capital. Oxford University Press, 1946

(4) Uma abordagem mais completa sobre o assunto é encontrada em: Martins, Eliseu. "Contabilidade Vs. Fluxo de Caixa". FEA/Usp - FIPECAFI. 1989.

(5) Sobre o assunto é indispensável à leitura de dois excelentes trabalhos:

a) Edwards, Edgar \& Bell, Philip W. "The Theory and mensurrement of Bussines Income". University of California Press, 1961. 
b) Martins, Eliseu. "Reposição, Inflação Própria e Inflação geral". Trabalho apresentado no XIII Congresso Brasileiro de Contabilidade, 1988.

As idéias básicas foram inspiradas neste trabalho.

(6) Martins, Eliseu. Op. Cit. 